\title{
Cultura política y partidos en Jalisco
}

Introducción

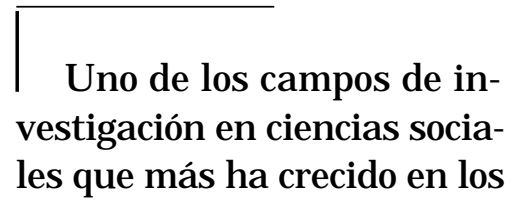

El presente trabajo es un intento de análisis y reflexión sobre la cultura política de uno de los componentes de to do sistema político que se precie de ser democrático (al menos formalmente): los partidos políticos. Se estudia la cultura política de los partidos políticos en Jalisco a partir del análisis de las representaciones y valores que los partidos políticos tienen sobre la democracia interna, para después contrastarlas con algunas prácticas referentes al liderazgo, dirección y formas de competencia. D ebido a que las dimensiones de la democracia son muy amplias y variadas, nos centramos en dos indicadores: la forma en que se da la competencia por los cargos de dirección interna y el carácter de la dirección y el liderazgo.

- Egresado de la maestría en Ciencias Sociales de la U niversidad de G uadalajara. solracbixbie@ hotmail.com últimos 30 años es, sin duda alguna, el de la cultura política. El término de cultura política ${ }^{1}$ casi siempre se ha relacionado al estudio de las percepciones de los ciudadanos sobre los sistemas políticos en donde habitan. Para Almond y Verba, la cultura política se refiere a "las orientaciones y actitudes específicamente políticas hacia el sistema político y sus diversos componentes y hacia las actitudes hacia el rol de sistema... cuando hablamos de la cultura política de una sociedad, nos referimos al sistema político tal como es interiorizado en elementos cognoscitivos en sentimientos y evaluaciones de su población" (Almond y Verba, 1970). La preocupación central de la cultura política radica en conocer "de qué manera percibe una población el universo de relaciones que tienen que ver con el ejercicio del mandato y la

$1 \mathrm{~N}$ os referimos al concepto de cultura política que tiene que ver con los valores, concepciones, actitudes y prácticas que se orientan hacia el ámbito específicamente político. 
obediencia, y cómo las asume, qué tipo de actitudes, reacciones y expectativas provoca, y de qué manera éstas tienen un impacto sobre el universo político" (Peschard, 1994:10).

Pero a la par de esta tendencia, poco a poco se ha venido formando una corriente de estudios cuyo contenido central ya no es el estudio de la cultura política del sistema político en su conjunto, sino que se centra en la reflexión y el análisis particular de las instituciones y organizaciones que componen dichos sistemas. Se trata de entender la cultura política de todo un sistema político partiendo del reconocimiento de la existencia de las diferentes culturas políticas de cada una de estas instituciones u organizaciones. Incluso hay autores que hablan de subculturas políticas como identidades de grupo basadas en un estilo de vida, una organización y una ideol ogía propias que se gestan dentro de la sociedad misma (Adler y Melnick, 1994).

El presente trabajo es un intento de análisis y reflexión sobre la cultura política de uno de los componentes de todo sistema político que se precie de ser democrático (al menos formalmente): los partidos políticos. El estudio de los partidos políticos ofrece un amplio margen de elementos estructurales que determinan la condición y funcionamiento tanto hacia su interior como frente a la sociedad en su conjunto. Reconocemos que, para determinar el verdadero impacto que tienen los partidos políticos en la cultura política de una sociedad, es necesario estudiarlos hacia dentro (de su organización interna) y hacia fuera (en la forma en que interactúan con el conjunto de la sociedad, el gobierno, otros partidos).

Como un primer acercamiento nos interesa estudiar la cultura política de los partidos políticos en J alisco a partir del análisis de las representaciones y valores que los partidos políticos tienen sobre la democracia interna, para después contrastarlas con al gunas prácticas referentes al liderazgo, dirección y formas de competencia. Esto nos permitirá identificar si en realidad existe congruencia entre los 
el ementos subjetivos y objetivos de la cultura política de los partidos políticos con mayor índice de votación en J alisco (Partido Revolucionario Institucional, Partido Acción Nacional y Partido de la Revolución Democrática). Debido a que las dimensiones de la democracia son muy amplias y variadas, nos centraremos en dos indicadores: la forma en que se da la competencia por los cargos de dirección interna y el carácter de la dirección y el liderazgo.

Si bien la existencia de partidos políticos (y por ende de su cultura política) en J alisco se remonta hasta principios del sigloxx, centraremos el análisis a partir de 1995, año en el que por primera vez se presenta la alternancia en la titularidad del Ejecutivo por parte de un partido político de oposición. Según cifras oficiales, el PAN logró la gubernatura de $\mathrm{J}$ alisco con el $52.71 \%$ de los votos por $37.09 \%$ del PRI y el $3.98 \%$ del PRD. Acción Nacional obtuvo 52 presidencias municipales, 17 diputaciones de mayoría y 7 de representación proporcional. Ante esta situación se pensaba que el crecimiento de Acción Nacional en J alisco tendría un efecto prolongado y que el PRI, por su parte, prolongaría su disminución en la presencia política del territorio estatal.

Pero en las elecciones locales de 1997, el panorama político-electoral del estado cambiaría de manera drástica cuando el PAN sufre un retroceso con respecto a los resultados aplastantes de 1995: alcanzó sol amente 9 de las 20 diputaciones de mayoría y menos de la mitad de los municipios. EI PAN consiguió el $40.66 \%$ de la votación, el PRI el $36 \%$ y el PRD el $15.38 \%$. Indiscutiblemente, el gran perdedor en esta contienda electoral fue el PAN, mientras que el PRI y el PRD obtuvieron resultados positivos que les permitieron volver al escenario político en condiciones de diálogo y negociación efectivos con el partido mayoritario.

Estos acontecimientos políticos, desde nuestro punto de vista, plantearon nuevos escenarios políticos anteriormente inusitados que requerían de adaptaciones y cam- 
bios en el funcionamiento y democracia interna de los partidos políticos.

Representaciones y valores

de los partidos políticos

Las representaciones son los principios organizadores de las posiciones adoptadas en las relaciones simbólicas entre actores sociales, posiciones que van ligadas a las inserciones específicas de estos actores en un conjunto definido de relaciones sociales (Doise, 1991).

En otras palabras, las representaciones sociales son productos socioculturales que emanan de la sociedad y que nos informan sobre las características de la propia sociedad. Algunas de las funciones más importantes de las representaciones sociales son: integración de novedades en el pensamiento social; orientación de la postura que tomará una persona ante el objeto representado y determinación de las conductas hacia dicho objeto; descripción, clasificación y explicación de fenómenos de las realidades cotidianas, con la suficiente precisión para que las personas puedan desenvolverse en ellas sin tropezar con demasiados contratiempos (I báñez, 1998).

Una de las mejores formas para conocer las representaciones de los partidos políticos en cuanto a elementos constitutivos de una democracia representativa (igualdad, libertad, soberanía, Estado, nación, justicia, etc.) es a través de sus documentos básicos y, específicamente, de su declaración de principios. Estos documentos son de carácter nacional y se deben acatar en todos los órganos de dirección y ejecución del partido correspondiente. Para el caso de J alisco no hay excepción.

Los valores son criterios de orientación de la acción social. Ellos determinan las metas legítimas hacia las que se orientan las conductas de los individuos y las colectividades. En- 
tre las intenciones y su objeto, los valores tienen como papel definir lo que es preferible y correcto, y contribuyen de esta manera a una toma de decisiones entre determinadas alternativas sociales o individuales. Suele definirse a los valores como creencias duraderas de que ciertas metas en la vida, objetos sociales o determi nados modos de conducta son, individual o colectivamente, preferibles a otros. En este sentido, los val ores son factores rel evantes de una cultura, o bien de la personalidad individual, que determinan las diversas maneras, la conducta de las personas y el curso económico, político y cultural de una sociedad (Cortés y Shybia, 1999).

Los valores de los partidos políticos los podemos encontrar comúnmente en los discursos partidarios, tomas de postura, documentos del partido o en entrevistas a actores vinculados a los partidos políticos (militantes, líderes, simpatizantes).

A continuación presentamos una aproximación en cuanto a representaciones y valores sobre democracia interna de los partidos políticos. Si analizamos de manera general el contenido de la declaración de principios de los tres partidos, podremos observar cómo se toca de manera indirecta la vida y democracia internas partidarias. Pero analicemos las representaciones de los partidos en torno a un concepto que aparece en las declaraciones de principios de todos los partidos y que nos será de gran utilidad para entender la forma en que conciben la democracia interna: nos referimos al concepto mismo de democracia.

\section{Partido Revolucionario Institucional}

EI PRI se considera como "un partido político nacionalista, democrático y popular que lucha dentro del Estado de derecho por obtener y conservar el poder público con la finalidad de defender la soberanía, avanzar en la democracia a la construcción de un mundo en el que imperen la paz, la cooperación y el respeto entre los pueblos" (PRI, 1999:6). 
Se habla de un partido que avanza de acuerdo con la sociedad: de ser un partido que alienta a la sociedad a lograr el desarrollo revolucionario y la consolidación institucional, a un partido que propicia y acata la voluntad democrática de la sociedad y que, consecuentemente, impulsa su propia democratización.

Para el PRI, la democracia establece que es el pueblo quien ha de elegir a sus gobernantes, dirigir el diseño de la política gubernamental y vigilar que los poderes de gobierno cumplan sus responsabilidades, respondan a la voluntad de la mayoría y respeten los derechos de las minorías. De acuerdo con esto, asumen como fuente de legitimidad del poder público el voto libre y universal. Finalmente, adoptan una concepción de democracia que rebasa la concepción el ectoral o procedimental, ya que sostienen que "la democracia es un sistema de vida que ha de extenderse al ámbito de lo social y lo económico" (I bid:7).

Partido Acción N acional

Con respecto al PAN, en su dedaración de principios, que data desde 1939, no aparece el concepto de democracia como tal; no es sino hasta 1965 cuando este partido el abora una proyección de los principios de doctrina donde se incluirían conceptos como democracia, partidos políticos, Estado, política, etc.

Para este partido político, la democracia requiere la participación eficaz de las personas en las actividades colectivas. Porque la democracia "como sistema de vida y de gobierno se funda en la igual dad esencial de todos los seres humanos; es la forma superior de legitimación del poder político y el sistema óptimo para respetar la dignidad humana que, en lo material, debe sostenerse en la suficiencia económica de todos y, en lo espiritual, en la posi bilidad real de acceso a los valores de la cultura y en el respeto a la libertad del hombre para responder ante su conciencia y ante Dios, del propio destino y del de sus semejantes" (PAN, 1999:19). 
Expresan la idea de que todo régimen democrático debe respetar, promover y garantizar el ejercicio real de los derechos fundamentales de la persona: derecho a la vida, a las libertades espirituales, a la justicia, a la educación y a la cultura, al trabajo y al descanso, a la propiedad, a la seguridad social, a la salud y al bienestar.

Desde la ideología del PAN, toda persona tiene derecho a intervenir en los asuntos públicos de la comunidad política de que forma parte. Por eso, 'todo régimen democrático debe respetar, promover y garantizar, mediante procedimientos electorales imparciales y objetivos, la expresión y representación de las minorías, los derechos del ciudadano para intervenir en el proceso de integración del gobierno al que vive sujeto y a formar parte del propio gobierno, y debe asegurar a los ciudadanos la libertad de información y su libertad de criticar a quienes ejercen el poder" (I dem).

Partido de la Revolución D emocrática

A pesar de ser un partido joven, el PRD constantemente ha sometido a reformas y modificaciones sus documentos básicos. En el cuarto Congreso Nacional, realizado en marzo de 1998, este partido modificó de manera importante su dedaración de principios. En estos nuevos documentos, el PRD asume que la democracia constituye el único medio legítimo de dirimir las diferencias en el seno de la comunidad, así como la forma principal de decidir sobre el rumbo que tome la nación en su conjunto.

EI PRD se reconoce como un partido político que conduce sus actividades por medios pacíficos por la vía democrática. Se rige por "principios y procedimientos democráticos en su interior. Se compromete con el principio de que sea la mayoría de sus afiliados quien decida sobre su programa y orientaciones políticas, sin menoscabo del respeto a la pluralidad, diversidad y del derecho de todos sus integrantes a ser representados. El partido se compromete a desarrollar el ejercicio 
de la crítica y la autocrítica con el método a través del cual puede lograrse el reconocimiento de las deficiencias y requerimientos de su lucha, de los problemas que sufre la sociedad mexicana toda, y de la búsqueda de un camino común para superarlos. El derecho a la información, el derecho a la libertad de expresión y el derecho a la crítica deben salvaguardarse como condición primordial de una transformación democrática verdadera" (PRD, 1999:4).

Este partido se compromete con la búsqueda de soluciones justas, equitativas e induyentes en los conflictos y, por ello, promueve acciones que tiendan a cambiar la defensa de los derechos individuales y colectivos, de la identidad y del derecho a la diferencia.

A partir de la representación que los partidos tienen del concepto de democracia es posible realizar un análisis de la forma en que conciben el ámbito democrático interno, ya que para todos los partidos aquí analizados, la democracia rebasa la esfera de lo el ectoral, lo procedimental, es decir, que la conciben no sól o como un procedimiento o mecanismo que permite, a partir de la realización de procesos electorales en condiciones de competencia, imparcialidad y transparencia, obtener el poder público o el control de las estructuras de dirección internas, sino también como una forma de vida. Esta concepción de democracia como forma de vida tiene que ver con la aplicación y prevalencia de prácticas cotidianas que garanticen la libre participación de sus integrantes, la aceptación de diferentes puntos de vista, así como el reconocimiento del debate y la discusión de todos los que deseen participar como únicas vías para llegar a acuerdos y decisiones. Y uno de los lugares donde se debe poner en práctica es, sin lugar a dudas, en el interior de los partidos políticos.

Continuando en el plano subjetivo de la cultura política, veamos al gunos ejemplos de los val ores de los partidos sobre su democracia interna. Aquí utilizaremos entrevistas reali- 
zadas a dirigentes estatales de los partidos políticos que reflejen su sentir con respecto al tema ya mencionado. ${ }^{2}$

A semanas de que se realizara la contienda para elegir al entonces presidente del PRI, uno de los contendientes (y futuro ganador), F rancisco Morales Aceves, comentó que el asunto de la democracia interna en los partidos políticos es "parte de la soberanía de cada organización política, con dos ingredientes fundamentales: hacia dentro de la organización deben ser procesos limpios, creíbles, de amplia participación y de una gran respetabilidad en la medida en que sean incluyentes y que aspiren a conquistar la unidad de la mayoría, y hacia fuera de la sociedad que sean respetados y apreciados los procesos internos de los partidos" (La Brecha, 1998).

Por su parte, el presidente del PRD en J alisco, Gilberto Parra Rodríguez (que fungió como tal de 1995 hasta mediados de 1998), reflexionó en torno a los cuestionamientos sobre la forma en que este partido pensaba arribar a un proceso de mayor institucionalización y democratización interna, a pesar de ser un partido compuesto por numerosas y diferentes corrientes. En estos térmi nos, Parra aceptó que 'tanto la institucionalización como la democratización interna son procesos largos que no se agotan en pocos años. Las corrientes tienen la legalidad que el estatuto del partido les confiere, el problema es que todavía falta mucha madurez para que las corrientes contribuyan a la democratización e institucionalización del partido. Lo que afecta el avance de la institucionalización y democratización del partido son las divisiones internas y los protagonismos negativos" (La Brecha, 1998a).

En la última contienda para renovar la dirigencia del PAN, en mayo de 1999, los dos candidatos a dirigentes estata-

2 C abe señalar que, desde 1995 a la fecha, to dos los partidos políticos analizados han renovado sus dirigencias, por lo que algunas entrevistas corresponden a los dirigentes actuales 0 a los anteriores. Más adelante retomaremos la cuestión de la renovación, para observar las prácticas en cuanto a las formas en que se da la competencia por las dirigencias partidarias. 
les, Gildardo Gómez Verónica y E milio González Márquez (quien es el actual dirigente), opinaron en torno a que si este partido era un instituto suficientemente democrático como para dar espacios de participación a las corrientes internas. Ambos señalaron que, efectivamente, el PAN era un partido suficientemente democrático y que al interior de este partido se reclamaba por espacios para que todos pudieran participar. De manera similar señalaron la existencia de una diversidad de formas de plantear los caminos a seguir por distintos liderazgos y la necesidad de reconocer la pluralidad (La Brecha, 1999).

Resumiendo las val oraciones sobre la democracia interna podemos decir que en el PRI se reconoce la democracia interna como una cuestión de soberanía de cada organización, pero con la condición de cumplir con procesos transparentes e incluyentes hacia dentro y creíbles y respetados hacia fuera. Con respecto al PRD se reconoce que, para tener una plena democracia interna, se requiere de periodos largos y que, en este partido, esta democratización se ve obstaculizada por las divisiones y protagonismos internos. EI PAN, por su parte, expresa tener democracia interna pero admite la necesidad de reconocer la pluralidad de corrientes internas.

Prácticas de los partidos:

dirección y liderazgo

Una vez analizadas las representaciones y valores de los partidos políticos sobre democracia interna, analizaremos sus prácticas centrándonos en dos indicadores: la forma en que se da la competencia por los cargos de dirección interna y el carácter de la dirección y el liderazgo. Este ejercicio nos permitirá detectar incongruencias entre lo que se piensa y dice, y entre lo que se hace.

A partir de los resultados en la elección de 1995, y ya como partido de oposición, el PRI replanteó sus estrategias para 
reconquistar el poder político de la entidad, lo que de al guna manera implicaba cambios en el funcionamiento interno. $Y$ los cambios no se hicieron esperar. En los trabajos de reorganización, las bases priistas demandaron a la directiva democracia interna y balance de sus acciones. Los militantes exigieron les fuera reconocido el derecho a elegir de manera directa a sus representantes y a los candidatos a puestos de elección popular. Casi la mayoría de los comités municipales, distritales y seccionales fueron reestructurados, eligiendo, en casi todos, una nueva directiva, para lo cual se tomó en cuenta la mayor de las veces a la militancia del partido. La nueva dirigencia encabezada por Correa Ceseña respondió favorablemente a estos redamos, con lo que el partido se fortalecería después de la crisis causada por la derrota el ectoral. EI hecho de que el PRI ya no gobernara en el estado y, en consecuencia, que el jefe del PRI ya no fuera el gobernador, le permitió construir a Correa un liderazgo fuerte (Hurtado y Valdéz, 1998:219-232).

Desde marzo de 1998 y hasta mediados del año 2000, el presidente del comité directivo estatal del PRI fue Francisco Morales Aceves, quien contendió para este cargo en un proceso electoral donde se permitió la participación libre y abierta de todos los militantes de este partido. Esto le otorgó una gran legitimidad frente a la sociedad y a su partido, que se tradujo en un fuerte liderazgo.

Durante ese lapso, el PRI aparecía en J alisco como un partido preocupado por recobrar la confianza y apoyo del electorado para volver a conseguir el poder político. Y para recuperar esta confianza ha sido capaz de reorganizar gran parte de su estructura interna, dotándola de procedimientos de el ección de dirigentes cada vez más democráticos.

¿Se puede hablar entonces de una cultura política verdaderamente democrática al interior del PRI? A pesar de que en apariencia los resultados muestran coherencia entre las representaciones, los valores y las prácticas de este partido en 
términos de democracia interna en cuanto a competencia por los cargos de liderazgo, aún hay una estructura fuertemente jerarquizada y permeada por poderosos grupos de poder que se vinculan a grupos nacionales muy autoritarios y conservadores. El liderazgo al interior de este partido, aunque es de tipo electo, está muy central izado en la figura del presidente estatal, quien ejerce un liderazgo fuerte frente a las demás estructuras partidistas.

Podemos hablar de un partido que, con la derrota de 1995, fue capaz de liberalizar procesos de el ección interna que abrieron la posibilidad de participación a un mayor número de militantes, pero que no modificaron de forma sustancial las estructuras corporativas que ejercen el control real del partido. Y estas características son propias de una cultura política de simulación (democrática).

Es un reto inmediato para el PRI convertirse en un partido con verdadera democracia interna, es decir, un partido con mandos descentral izados que no cambie cada vez que necesite la confianza y apoyo de los ciudadanos para recuperar el poder, sino que cambie en el sentido de ser un partido que realmente exprese las demandas de la sociedad y se interese por ella.

La cultura política del PAN no goza de mejor salud que la del PRI. A partir del triunfo electoral en 1995, el PAN se ha visto inmerso en una serie de conflictos de dirección y liderazgo internos como consecuencia de una lucha constante por el control político del partido entre las principales corrientes que lo conforman. Uno de los conflictos internos más sonados fue el que se conformó a raíz del reciente proceso de selección interna del presidente estatal.

EI 13 de diciembre de 1998 se suspendió una asamblea estatal por falta de consensos en la integración de los consejeros que elegirían al próximo dirigente estatal. El 21 de febrero de 1999, después de una serie de negociaciones, se reanudó la asamblea, dando como resultado una lista en la 
que el anterior comité estatal (encabezado por Herbert Taylor) conservó su supremacía. Este conflicto se agravó cuando el Comité Ejecutivo Estatal se negó a ratificar a tres consejeros integrantes del denominado grupo Zapopan (grupo contrario al del comité estatal), comandado por el ex secretario general de gobierno, Raúl Octavio Espinoza. Al final se ratificó sólo a uno de estos consejeros y el triunfo fue para el candidato del comité estatal: Emilio González Márquez.

Existen graves discordancias entre las representaciones y las prácticas democráticas internas. En primer lugar, no hay posi bilidad de que todos los miembros de este partido participen en la selección de sus candidatos. En cuanto a la existencia de corrientes, no se permiten estas figuras ni las críticas y el debate de ideas al interior de este partido. La dirección es sumamente centralizada y vertical, ya que las decisiones las toma la pequeña élite en el poder. La directiva nacional tiene un peso exagerado sobre los demás órganos, lo que genera una marginación de las bases del partido.

La contradicción entre sus principios, valores y prácticas es considerable. Urge iniciar un proceso de democratización interna, una descentralización de la toma de decisiones y, sobre todo, el derecho y la libertad de formar corrientes al interior que les permitan expresar libremente sus ideas y propuestas.

Finalmente, el PRD adolece de varios problemas que limitan la democracia interna. A pesar de ser el partido que reconoce de manera más directa en su dedaración de principios la necesidad de democracia interna, de aceptar la participación de la ciudadanía en sus comicios y de reconocer abiertamente la existencia de conflictos que minan la posibilidad de tener plena democracia interna, la cultura política de este partido no es muy halagadora en términos democráticos.

Casi desde su aparición en J al isco, este partido se ha visto inmerso en una lucha constante entre distintos grupos y corrientes internas por el control del partido y por las candida- 
turas a cargos de elección popular (especialmente los puestos para cargos que se eligen por el principio de representación proporcional). "Cada corriente o grupo entiende la democracia interna como la posibilidad de conseguir puestos a costa y sobre los contendientes. Cuando algún grupo gana, el perdedor ya no se integra en la acción conjunta del partido" (Alonso, 1996). Además, este partido se caracteriza por un fuerte liderazgo centralizado desde el Comité Ejecutivo Nacional, quien constantemente toma decisiones por él.

A partir de 1995, este partido ha visto incrementar su votación de manera considerable (de 3.98\% en las elecciones de 1995, hasta $15.38 \%$ en los comicios de 1997). Y junto con este incremento electoral también se incrementaron los conflictos internos de dirección. Para la el ección de presidente del Comité Ejecutivo Estatal en 1995 se tuvieron que aplazar las elecciones (programadas para el 22 de octubre) hasta el 28 de enero de 1996, pero se volvieron a posponer hasta el 18 de febrero, alegando "razones políticas" y de carácter interno. El ganador de esta el ección fue Gilberto Parra, quien desempeñó un liderazgo muy debilitado, como producto de la constante lucha interna. Durante su gestión se realizaron importantes alianzas en términos el ectorales con El Barzón y con el Grupo Universidad de Raúl Padilla, mismas que fueron fuertemente cuestionadas por importantes corrientes y grupos del partido, ya que esto demostraba una actitud pragmática y electorera.

Después de una el ección impugnada en junio de 1998, que se tuvo que repetir en noviembre del mismo año, con lo que el partido se mantuvo acéfal o y prácticamente inactivo durante casi seis meses, el actual presidente del Comité Estatal es Claudio Palacios, quien no goza de mejor fortuna, en términos de liderazgo, que su antecesor.

Mientras que en el PRD no exista el respeto a las corrientes minoritarias y se acepte el debate, el diálogo y la discusión como canales para llegar a consensos, difícilmente 
podremos hablar de un partido con una cultura política democrática. Lo mismo sucede en términos del fuerte liderazgo: si esta cultura vertical y centralizada prevalece, este partido seguirá viviendo una aparente democracia interna.

Si un partido político con una verdadera democracia interna es el que "en su seno se respetan y garantizan los derechos fundamentales de los afiliados, aplicando medidas, mecanismos y controles para velar por dicha garantía y teniendo siempre en consideración val ores tales como la libertad, la igual dad, la justicia y el pluralismo democrático" (Cárdenas, 1992:68), no podemos afirmar que ésta sea la situación actual de los tres partidos políticos aquí analizados. La cultura política de los partidos políticos en J alisco está lejos de ser de tipo democrático, al menos en la forma en que interiorizan y hacen operativa la democracia en sus estructuras de dirección y liderazgo. Hace falta acortar las distancias entre las representaciones y los valores por un lado, y las prácticas políticas de dirección y liderazgo de los partidos políticos, por otrolado.

"Si la democracia interna de los partidos po líticos no se conso lida, no habrá una transformación sustancial en la cultura política nacional. La ampliación de la vida democrática en los partidos repercute en la democratización de la misma sociedad" (Idem).

Los partidos todavía son instrumentos para la rotación de puestos públicos y para la búsqueda de la representación política; pero tienen el reto de responder a la construcción democrática no sól o hacia fuera, sino también en su propia vida interna.

\section{Postcriptum}

Buena parte del análisis aquí planteado sobre la cultura política de los partidos políticos en J alisco se ajusta a las condiciones prevalecientes hasta antes del proceso electoral 
federal que concluyó el día 2 de julio de 2000, con una serie de resultados nunca antes experimentados: por primera vez, en más de setenta años, un partido político de oposición obtiene la titularidad del Poder Ejecutivo, lo que plantea la posibilidad de que tanto la estructura como el funcionamiento del gobierno ya no opere de acuerdo a las necesi dades del PRI. Los resultados electorales marcan una composición inédita en el Poder Legislativo: el PRI no consiguió la mayoría absoluta en el Senado y, por segunda vez consecutiva, ningún partido político obtiene la mayoría absoluta en la Cámara baja, lo que posibilita la negociación y discusión de los grandes problemas del país entre todos los actores políticos con representación parlamentaria.

A la luz de estos acontecimientos, las expectativas sobre la cultura política partidaria innegablemente se han modificado tanto en el plano nacional como en el local y, por ende, cabría hacer al gunas consi deraciones que consideramos pertinentes para cada uno de los partidos políticos analizados.

Inmediatamente después de las el ecciones del 2 de julio, en el PRI comenzaron los problemas en la dirigencia estatal: el formato inicial planteado para una elección abierta y democrática entre los precandidatos a la gubernatura del estado se modificó completamente, ya que al final se optó por sacar a un candidato, como en la larga tradición priista, de "unidad". Los motivos de este cambio abrupto no se hicieron esperar: algunos lo justificaron por cuestiones económicas, otros por la necesidad de evitar un desgaste entre los militantes y las bases, otros por la fuerza que pudiera obtener el precandidato ganador y el partido mismo frente a la ciudadanía.

Una vez realizada la convención para elegir al candidato priista, J orge Arana, los compromisos políticos pactados con los otros precandidatos al gobierno de J alisco, Enrique I barra y J osé Luis Leal Sanabria, empezaron a causar conflictos internos, ya que en el registro de planillas municipa- 
les y de candidatos a diputados por los dos principios de representación, los acuerdos pactados no se cumplieron de manera cabal. Estos acontecimientos han ensombrecido la aparente democratización interna que reflejaba este partido; los conflictos internos y las escisiones de algunos grupos y sectores, antes incondicionales para el PRI, denotan una situación de crisis interna y de necesaria recomposición estructural.

Para Panebianco, una derrota electoral es la primera fase de un cambio organizativo, entendido como la alteración en un partido de su estructura de autoridad. La sustitución de la coalición dominante y la transformación de las reglas internas, de los objetivos y jerarquías, son las etapas que concluyen el cambio activado (Panebianco, 1982). Si el PRI logra aprovechar esta situación política para eliminar de una sola vez los elementos característicos de un partido hegemónico y autoritario, cada vez más disfuncionales y nocivos para su vida interna, y modificar su estructura de liderazgo y dirección vertical por una detipo horizontal y participativa, el futuro de este partido será prometedor; de lo contrario seguiremos presenciando su descomposición y probable desaparición del escenario local.

La situación que presenta el PAN en J alisco es completamente diferente a la del PRI. Podríamos decir que, en términos de dirección y liderazgo interno, no sufrieron modificaciones importantes: no se dieron cambios en la dirigencia estatal; la elección interna del candidato a la gubernatura del estado se realizó sin problema al guno y los conflictos internos, aunque no se han solucionado, por lo menos ya no generan tantas expectativas negativas para la sociedad. Sin embargo, con el triunfo de F ox, y con una preferencia hasta la fecha favorable hacia el candidato panista Francisco Ramírez Acuña, el PAN tiene la gran tarea de modificar, de la misma forma que el PRI, los lineamientos de dirección y liderazgo interno que permitan una mayor participación de sus 
militantes y simpatizantes en las políticas a seguir durante los próximos seis años. La tarea inmediata es no caer en la misma lógica que el PRI cuando fue gobierno: al ejarse de las bases y mantener una política vertical de control y dirección del partido.

Para el PRD, el panorama no pinta nada bien, puesto a raíz del fracaso electoral de 2000, ya que, tanto a nivel federal como estatal, sufrió una caída con relación a la de 1997. Son muchas las razones que originaron este proceso, pero principalmente podemos señalar dos: las elecciones internas para dirigente estatal y las posteriores escisiones y fracturas de las filas de este partido y la lucha entre facciones por candidaturas (principalmente entre el grupo Universidad y algunos grupos fundadores del PRD).

Las condiciones actuales parecen no cambiar en este partido, ya que los conflictos internos preval ecen; las escisiones son cada vez más continuas y no se observa, por lo menos a corto plazo, la voluntad de la dirigencia perredista por adecuar y reformar los vicios y errores que se han cometido durante más de tres años. La presencia política del PRD en J alisco cada día es menor y, ante una escasa actitud de negociación y diálogo entre las bases partidistas, todo parece indicar que el resultado de los próximos comicios estatales, que se ve poco prometedor, obligará a este partido a cambiar; de lo contrario seguiremos presenciando un proceso de descomposición política que parece no tener arreglo alguno.

Bibliografía

Adler Lomnitz, Larissa y Melnick,Ana, La cultura política chilena y los partidos de centro, FCE, México, 1998.

Almond, G y yerba S., La cultura cívica, Euramérica, Madrid, 1970. 
A lonso,Jorge,"La difícil escalada a la democracia interna partidaria", en Ramírez, Juan Manuel y Alonso, Jorge (Coords), La democracia de los de abajo en Jalisco, U niversidad de Guadalajara, México, 1996.

Cárdenas Gracia, Jaime, Crisis de legitimidad y democracia interna de los partidos políticos, FCE, México, 1992, p. 68.

Cortés, Marco y Shibya, C ecilia, Los valores de los jaliscienses, Universidad de Guadalajara, México, 1999.

D oise,W illem, "Las representaciones sociales: presentación de un campo de investigación", en Revista Antropos N úm. 27, Barcelo na, 1991.

H urtado, Javier y Andrés Valdez, Democracia y poder político en Jalisco. Desde la alternancia hasta las elecciones locales de 1997, U niversidad de Guadalajara, México, 1998, pp. 219- 232.

Ibáñez,Tomás, Ideologías de la vida cotidiana, Sendai Ediciones, España, 1988.

- La Brecha, N úm. 17, febrero 16 de 1998.

- N úm. 21, marzo 16 de 1998a.

- N úm. 82, mayo 16 de 1999.

Panebianco, Ángelo, M odelos de partido, Alianza U niversidad, Madrid, 1982.

Partido Acción Nacional, Principios de doctrina y proyección de los principios de doctrina del Partido Acción Nacional, 1999, p. 19.

Partido de la Revolución Democrática,"Declaración de principios del Partido de la Revolución Democrática", 1999, p. 4.

Partido Revolucionario Institucional, "Declaración de principios del Partido Revolucionario Institucional", 1999, p. 6.

Peschard, Jacqueline, La cultura política democrática, IFE, México, 1994, p.10. 